\title{
Growth of the sika deer (Cervus nippon yakushimae) population in the western lowland forests of Yakushima Island, Japan
}

\author{
Riyou Tsujino ${ }^{1, *}$, Naohiko Noma ${ }^{2}$ and Takakazu Yumoto ${ }^{3}$ \\ ${ }^{1}$ Center for Ecological Research, Kyoto University, Kami-Tanakami-Hiranocho, Ohtu, Shiga 520-2113, Japan \\ ${ }^{2}$ School of Environmental Science, University of Shiga Prefecture, 2500 Hassaka-cho, Hikone 522-8533, Japan \\ ${ }^{3}$ Research Institute for Humanity and Nature, 335 Takashima-cho, Marutamachi-dori Kawaramachi nishi-iru, Kamigyo-ku, \\ Kyoto 602-0878, Japan
}

\begin{abstract}
The density of a sika deer population in an evergreen natural forest on Yakushima Island was surveyed by road counts from August 1988 to July 1989, and from August 2001 to July 2002. Based on distance-sampling methods, population density estimates were $2.55 \mathrm{deer} / \mathrm{km}^{2}$ in 1988 and $40.74 \mathrm{deer} / \mathrm{km}^{2}$ in 2001 . Encounter rate indices (number of deer seen per kilometer) increased by a factor of 6.16 over these 13 years. This rapid population growth may reflect increased sika deer food availability following logging in the forest.
\end{abstract}

Key words: deer density, distance-sampling, evergreen forest, road count, Yakushima Island.

Herbivorous mammals have considerable effects on growth and survivorship of woody plants and often disturb forest regeneration (Shaw 1968; Griffin 1971; Pease et al. 1979; Kikuzawa 1988; Takatsuki and Gorai 1994; Ida and Nakagoshi 1996; Akashi and Nakashizuka 1999). Influences include seed removal (Asada and Ochiai 1996; Weerasinghe and Takatsuki 1999), seedling and sapling grazing and browsing (Pease et al. 1979; Hobbs et al. 1981; Takatsuki and Gorai 1994; Shimoda et al. 1994; Tsujino and Yumoto 2004), bark stripping (Takatsuki 1990; Sekine and Sato 1992; Akashi and Nakashizuka 1999; Yokoyama et al. 2000), trampling (McCarthy and Facelli 1990), and digging or soil surface disturbance (Ickes et al. 2001; Bratton 1974; Tardiff and Stanford 1998). Impacts on vegetation structure are heavier as herbivore density increases.

The population size and range of sika deer, Cervus nippon TEMMINCK, have been increasing in Japan since the 1970s, and serious damage to agriculture and forest lands have been evident since the 1980s (Kaji 1995; Akashi and Nakashizuka 1999; Matsuda et al. 1999; Sakata et al. 2001). Previous studies have documented the effects of sika deer at high population densities on native vegetation (e.g. $60 \mathrm{head} / \mathrm{km}^{2}$ in a deciduous forest on Kinkazan Island, northern Japan, Takatsuki and Gorai 1994; 80 head $/ \mathrm{km}^{2}$ on Scaniport Estate, Scotland, McLean 1999; $29-31 \mathrm{head} / \mathrm{km}^{2}$ in a riparian deciduous forest, central Japan, Nomiya et al. 2003). On Yakushima Island, sika deer density reported between 1999 to 2001 was relatively high (43-70 deer/ $\mathrm{km}^{2}$ ) compared to those at other sites in Japan (Agetsuma et al. 2003). It was assumed that the population on Yakushima Island was increasing during this period, but systematic assessments of population status had not been carried out. Because of the concern that increased deer browsing may reduce tree recruitment (Akashi and Nakashizuka 1999), careful analysis of the sika deer population on Yakushima Island was called for. In this paper, we examine a long-term change in population density of sika deer in a lowland natural evergreen forest on Yakushima Island by using Distance-sampling methods and simple encounter rate indices, the number of deer seen per kilometer.

\section{Study area}

This study was conducted in the western part of Yakushima Island $\left(30^{\circ} \mathrm{N}, 131^{\circ} \mathrm{E}\right), 70 \mathrm{~km}$ south of

*To whom correspondence should be addressed. E-mail: turi@ecology.kyoto-u.ac.jp 


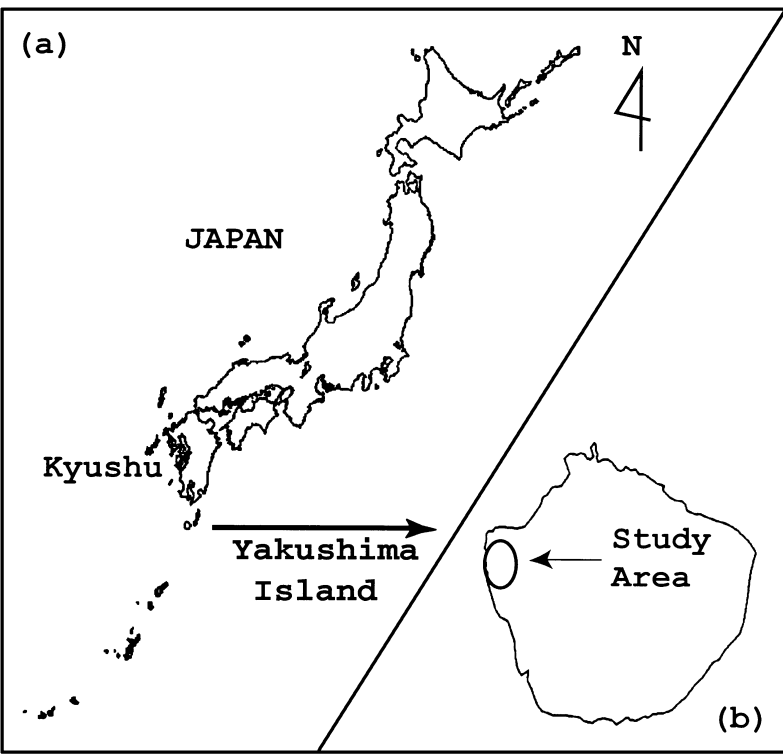

Fig. 1. Location of (a) Yakushima Island and (b) study area.

Kyushu, Japan (Fig. 1). The study area is a protected, natural, warm-temperate evergreen broad leaved forest and located from about $150 \mathrm{~m}$ to $180 \mathrm{~m}$ elevation. Forests consist mainly of Fagaceae, Myrsinaceae and Lauraceae tree species (Agetsuma 1995). Maximum tree height is about $12 \mathrm{~m}$ and $20 \mathrm{~m}$ at the ridge tops and the valleys, respectively (Noma 1997). There are a few small, isolated plantations of conifers Cryptomeria japonica (L.f.) D. Don (Agetsuma 1998). The mean annual temperature and the annual rainfall are $21{ }^{\circ} \mathrm{C}$ and $2600 \mathrm{~mm}$ respectively (Tagawa 1980).

An endemic subspecies of sika deer (Cervus nippon yakushimae Kuroda and Okada) occurs at a high population density (43-70 head $/ \mathrm{km}^{2}$ : Agetsuma et al. 2003) on Yakushima Island and also is found on Kuchi-noErabujima Island, a small volcanic island $12 \mathrm{~km}$ northwest of Yakushima Island. In the broad-leaved evergreen forests of Japan, sika deer feed primarily on the leaves and fruits of evergreen plants and graminoids (Takatsuki 1988, 1990; Asada and Ochiai 1996). C. $n$. yakushimae behaves as a browser in the lowland forests on Yakushima Island. On the island, there are no other herbivorous mammals, no natural predators, and hunting is prohibited in the study area.

\section{Methods}

\section{Road counts}

We conducted road side count series twice a year to

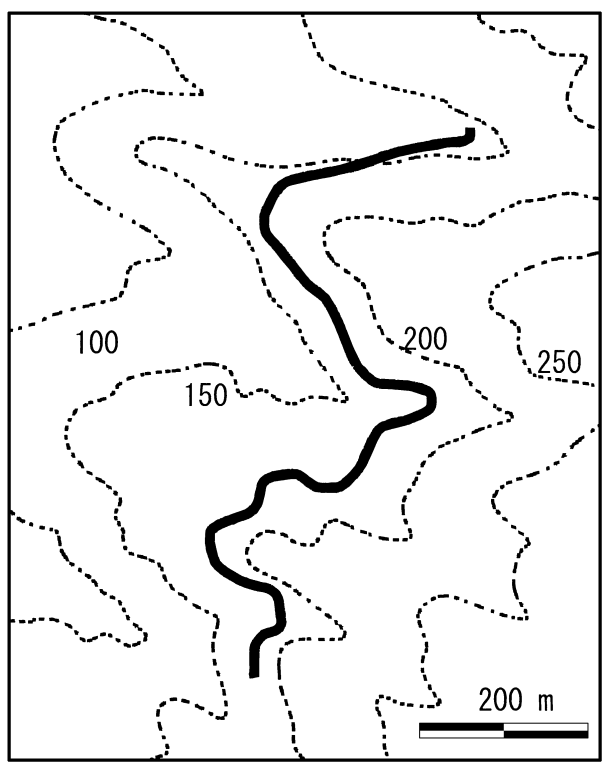

Fig. 2. Solid line shows roadside census routes in Hanyama region. Total length of the route was $1.2 \mathrm{~km}$.

estimate the densities and rate of change in the sika deer population from August 1988 to July 1989 and from August 2001 to July 2002.

A road four meters wide runs through the study area, with minimal impacts on vegetation (Agetsuma et al. 1994). Between 1989 and 2001, conditions along the census road changed. The road was paved with asphalt in the early 1990's. In 1997, a valley crossing the road washed out both the road and most of the trees nearby, prompting the construction of a bridge for the road at that crossing.

We established a road side census route of $1.2 \mathrm{~km}$ along the road through the forest in the Hanyama region (Fig. 2). Soon after sunrise, we walked the route at a speed of about $2 \mathrm{~km} / \mathrm{h}$. When we encountered deer, we counted the number observed, recorded the location on a map, and followed the direction they moved to in order to reduce the chance of double counting. We determined the perpendicular distances on the map from the closest approach distances to our curving transects (Hiby and Krishna 2001). Deer were classified into 3 age-sex classes: adult male ( 2 year or older), adult female ( 2 year or older) and young (0-1 year).

We conducted these surveys from 1-6 times a month, (46 times total) the first year (August 1988 to July 1989), and 3-7 times a month (58 times total) the second year (August 2001 to July 2002) at intervals of 2-25 days. Surveys were not carried out on rainy mornings or when strong winds were present. We did not record age-sex 
Table 1. Census efforts and number of deer recorded.

\begin{tabular}{lcccccc}
\hline Seasons & No. of Census & Adult male & Adult female & Young & Unknown & No. of observations \\
\hline 1st (Aug 1988-Jul 1989) & & & & & & \\
ASO & 16 & 1 & 0 & 0 & 5 & 6 \\
NDJ & 12 & 0 & 0 & 0 & 1 & 1 \\
FMA & 8 & 0 & 0 & 0 & 2 & 2 \\
MJJ & 10 & 0 & 0 & 0 & 4 & 4 \\
1-year & 46 & 1 & 0 & 0 & 12 & 13 \\
2nd (Aug 2001-Jul 2002) & & & & & & 37 \\
ASO & 13 & 4 & 0 & 0 & 36 & 31 \\
NDJ & 16 & 1 & 4 & 0 & 14 & 101 \\
FMA & 19 & 2 & 17 & 4 & 4 & 63 \\
MJJ & 10 & 6 & 21 & 4 & & \\
1-year & 58 & 13 & &
\end{tabular}

classes for observations before May 2002. Encounter rates of deer, the number of deer seen per kilometer, were classified into four seasons; ASO (August, September and October), NDJ (November, and December and January), FMA (February, March and April), and MJJ (May, June and July). We compared encounter rates among seasons and census series.

\section{Density estimate}

We estimated sika deer density, $D$, using the distancesampling method with Program DISTANCE 4.1 (Buckland et al. 1993; Thomas et al. 2003). Distance-sampling methods have been used widely to determine wildlife densities from sighting data (reviewed by Buckland et al. 1993). The critical data collected are distances to the observed animal from a line transect followed by the observers (Buckland et al. 1993). A large proportion of the animals may go undetected, but the theory allows accurate estimates of density to be made under mild assumptions (Buckland et al. 1993).

Since the number of available observations was limited, we estimated a pooled (within year) detection function, $g(x)$, where $x$ is the perpendicular distance and $g(x)$ is a detection function or the probability at which a deer at a perpendicular distance from the road was detected by observers. The truncation distance, $w$, was chosen for each data set so that the half-normal detection function $g(x)$ was near 0.15 (Buckland et al. 1993). We applied the following four key functions; uniform key (adjusted with cosine series and polynomial series), half-normal key (adjusted with hermite polynomials series), and hazard-rate key (adjusted with cosine series). We used Akaike Information Criterion (AIC) and selected the function with the minimum AIC as the best-fitted esti- mator. We accepted the selected model if it had a nonsignificant goodness-of-fit value. Deer group densities were estimated according to the general equation $D(S)=$ $n /(2 \times L \times \mathrm{ESW})$, where $n$ is the number of visual observations of deer groups, $L$ the total length, and ESW the effective strip width. Estimates of ESW were calculated from the detection function at zero distance. Sika deer are often observed in groups. Any possible bias in group size estimation was assessed by regressing group size (log-transformed) on the estimated detection function. Adjustment was then made if the regression was significant at $P \leq 0.1$ (Gill et al. 1997). If not, we used average group sizes.

\section{Results}

We made 8-16 census efforts in each three month season (Table 1). We observed 13 and 101 deer directly for the first and second series, respectively.

We found 0.20 groups per kilometer $(S D=0.50, n=$ $46)$ or 0.28 deer per kilometer $(S D=0.66, n=46)$ during one census trial in the first census series, and 1.17 groups per kilometer $(S D=1.53, n=58)$ or 1.74 deer per kilometer $(S D=2.63, n=58)$ during one census trial in the second census series. Mean group sizes of the two series were 1.44 deer $(S D=0.73, n=9)$ for the first series and 1.47 deer $(S D=0.95, n=68)$ for the second series. Mean group size of the first series was not significantly different from that of the second series (Mann-Whitney's $U$-test, $U=313.5, P=0.4419$ ).

\section{Density estimate}

For the first series, a Uniform model was selected for estimating deer density and the estimated truncation 
Table 2. Summary of candidate models used in the line transect analysis for sika deer on Yakushima Island. The models tested were UC (uniform key and cosine adjustment), UP (uniform key and polynomial adjustment), HN (half-normal key and hermite polynomial adjustment), and $\mathrm{HC}$ (hazard key and cosine adjustment).

\begin{tabular}{|c|c|c|c|c|c|c|c|c|c|}
\hline \multirow{2}{*}{ Model } & \multirow{2}{*}{ Adjustment terms } & \multirow{2}{*}{ AIC } & \multirow{2}{*}{$P$-value } & \multirow{2}{*}{ Density of group } & \multicolumn{2}{|c|}{ 95\% Confidence limits } & \multirow{2}{*}{ Density of deer } & \multicolumn{2}{|c|}{ 95\% Confidence limits } \\
\hline & & & & & Lower & Upper & & Lower & Upper \\
\hline \multicolumn{10}{|c|}{ 1st (Aug 1988-Jul 1989), $w=47$} \\
\hline $\mathrm{UC}$ & 0 & 69.02 & 0.739 & 1.76 & 0.85 & 3.67 & 2.55 & 1.15 & 5.63 \\
\hline UP & 0 & 69.02 & 0.739 & 1.76 & 0.85 & 3.67 & 2.55 & 1.15 & 5.63 \\
\hline $\mathrm{HN}$ & 1 & 70.99 & -1.00 & 1.86 & 0.71 & 4.90 & 2.69 & 0.98 & 7.37 \\
\hline $\mathrm{HC}$ & 2 & 72.98 & -1.00 & 1.92 & 0.53 & 6.95 & 2.77 & 0.75 & 10.25 \\
\hline \multicolumn{10}{|c|}{ 2nd (Aug 2001-Jul 2002), $w=26$} \\
\hline $\mathrm{UC}$ & 2 & 428.07 & 0.0993 & 28.00 & 17.31 & 45.31 & 40.94 & 24.98 & 67.10 \\
\hline UP & 1 & 429.27 & 0.0777 & 26.99 & 19.65 & 37.06 & 39.89 & 28.48 & 55.86 \\
\hline $\mathrm{HN}$ & 2 & 428.66 & 0.0873 & 28.47 & 17.06 & 47.52 & 41.85 & 24.78 & 70.69 \\
\hline $\mathrm{HC}$ & 2 & 427.22 & 0.0123 & 27.93 & 19.41 & 40.18 & 40.74 & 27.84 & 59.62 \\
\hline
\end{tabular}
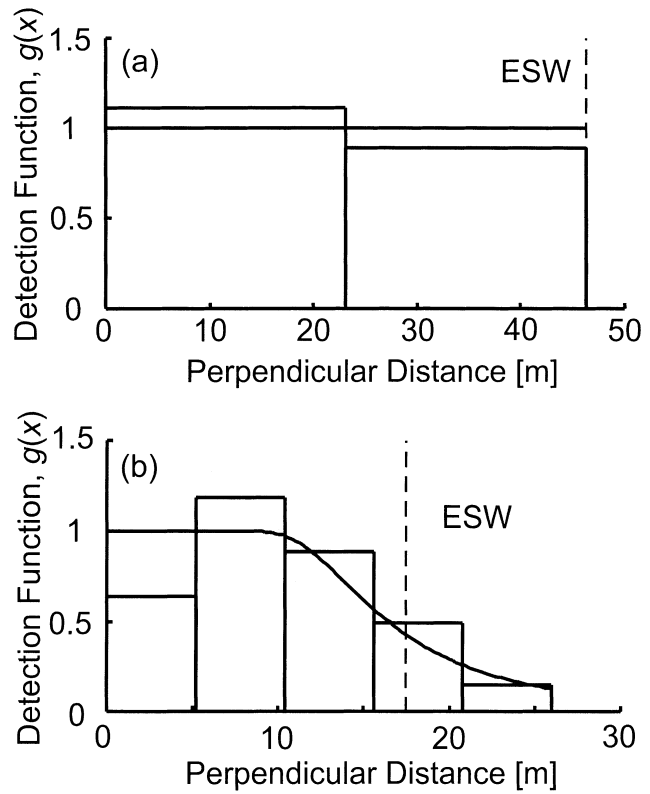

Fig. 3. Detection function (continuous line) plot, histogram of perpendicular distances, and effective strip width (ESW, broken line) for (a) the first series (uniform key), (b) the second series (hazard key and cosine adjustment).

distance, $w$, was $47 \mathrm{~m}$ (Table 2). The selected model (Fig. 3a) was characterized by ESW of $46.3 \mathrm{~m}(95 \% \mathrm{CI}$ : 46.3-46.3 m). We detected no significant relationships between $\ln$ (group size) and $g(x)(r=0, P=0.50)$. The tested $P$-value was greater than specified significance level of 0.1 , so the average cluster size, 1.44 deer/group ( $95 \%$ CI: 1-2.12 deer/group), was used for analysis. The estimates of group density and deer density were 1.76 groups $/ \mathrm{km}^{2}$ (95\% CI: $0.85-3.67$ group $\left./ \mathrm{km}^{2}\right)$ and 2.55 deer $/ \mathrm{km}^{2}$ (95\% CI: $\left.1.15-5.63 \mathrm{deer} / \mathrm{km}^{2}\right)$, respectively.
Table 3. Results of ANOVA on the differences of encounter rates with deer, the number of deer seen per kilometer, in two year-long series; the first series, from August 1988 to July 1989; the second series, from August 2001 to July 2002.

\begin{tabular}{lcccc}
\hline \multicolumn{1}{c}{ Source } & d.f. & Mean Square & $F$-value & $P$-value \\
\hline Series & 1 & 37.911 & 13.270 & $<0.001$ \\
Season & 3 & 5.720 & 0.666 & 0.575 \\
Series X Season & 3 & 2.434 & 0.850 & 0.470 \\
\hline
\end{tabular}

For the second series, a Hazard-rate model (adjusted by cosine key) was selected for estimating deer density, and the truncation distance, $w$, was $26 \mathrm{~m}$ (Table 2). The selected model (Fig. 3b) was characterized by and ESW of $17.49 \mathrm{~m}$ (95\% CI: 14.28-21.42 m). We detected no significant relationships between $\ln$ (group size) and $g(x)$ $(r=0.050, P=0.657)$. The tested $P$-value was greater than the specified significance level of 0.1 , so the average cluster size, 1.47 deer/group (95\% CI: 1.25-1.73 deer/group) was used for analyses. The estimates of group density and deer density were 27.93 group $/ \mathrm{km}^{2}$ (95\% CI: $19.41-40.18$ group $/ \mathrm{km}^{2}$ ) and 40.74 deer $/ \mathrm{km}^{2}$ (95\% CI: 27.840-59.621 deer $/ \mathrm{km}^{2}$ ) respectively.

Encounter rates of deer were significantly different between the two series, but were not significantly different between seasons (2-way ANOVA, Table 3, Fig. 4). The mean encounter rates of deer were $0.24(S D=0.55$, $n=46)$ for the first series and $1.45(S D=2.19, n=58)$ for the second series. The seasonal encounter rates were not significantly correlated between the first and the second series (Spearman's coefficient correlation test; $r s=0.53, P=0.50)$ 


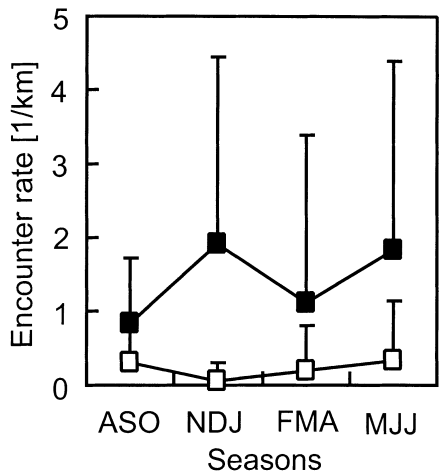

Fig. 4. Seasonal change in mean encounter rate indices, the number of deer groups seen per kilometer, in two year-long series; the first series (white square), from August 1988 to July 1989; the second series (black square), from August 2001 to July 2002. Error bars indicate SD. ASO, NDJ, FMA and MJJ indicate August to October, November to January, February to April, and May to July, respectively.

\section{Discussion}

The main concern with any line transect study is the validity of its assumptions (Focardi et al. 2002). Using roads as transects is questionable because of potential bias associated with either preferred use or avoidance of roads (Buckland et al. 1993; Ruette et al. 2003). However, cutting straight line transects through dense forest is time consuming and expensive when large areas need to be surveyed for rare or highly clustered species (Hiby and Krishna 2001). It may also be difficult to place straight line transects on roads, which potentially increases the difficulty of obtaining accurate perpendicular distance measurements (Anderson et al. 1979). The presence of barriers such as hedges alongside the road could lead to biased results because of the potential visual obstruction. In our study, the steep topography and dense evergreen broad-leaved forest diminished visibility into the forest from the road.

Density estimates around the road in this study (40.74 deer $/ \mathrm{km}^{2}$ in 2001) were not greatly different from those obtained in a forest-based estimate by Agetsuma et al. (2003) (43-70 deer $/ \mathrm{km}^{2}$ in 1999-2001). The degree of the habitat use and deer density around the road was probably lower than in the forest, because deer likely avoid the area when cars are on the road. In addition, the mean group size in our study (1.47 deer/group, 1-6 deer, $n=68)$ was similar to that by Agetsuma et al. (2003) (1.9 deer/group, $1-6$ deer, $n=175$ ).

Between the two series, rates of increase for density estimates and encounter rate were 15.98 and 6.16 , respectively. Partly because our observations during the first series did not constitute an adequate sample size (at least 40 observations for density estimate, Buckland et al. 1993), we could not estimate a detection function and ESW. The density estimate for the first series was not sufficient and density estimate comparisons should not be made. However, we repeated enough census trials to estimate encounter rates for these two series, so the following discussion is based on increasing rate of encounters between the series.

Encounter rates increased by a factor of 6.16 over the 13 years captured in the study, with an average annual rate of change of 1.15. If this reflects actual change in population density, it is not outside the range of population growth rates reported for sika deer $(13.6 \%$ per year and $16-21 \%$ per year for Cervus nippon yezoensis (Kaji 1995; Matsuda et al. 2002)).

Population growth may reflect increased survival because sport hunting has been prohibited since 1971 (Kagoshimaken Sizen-aigo Kyokai 1981). Deer on Yakushima Island are also usually free of the stress of heavy snows and cold reported for more northern populations (Uno et al. 1998).

Impacts on wildlife of logging and conversion of natural forests to plantations forests are well documented (Agetsuma 1999). Food availability for herbivorous animals increases rapidly during the first several years after logging, but 15 to 25 years later, the food supply greatly decreases (Agetsuma 1999). Population growth that we are seeing today may reflect changes in habitats following logging that has occurred since the 1960s. Conversion to plantation forests could also have affected the distribution of deer on the island, with a shift toward the western lowland forests. Evergreen broad-leaved forests in the zone between 100 to $700 \mathrm{~m}$ above sea level have not been logged, although there had been logging within $2 \mathrm{~km}$ of the study area (Miura 1984).

Agetsuma et al. (2003) reported that vegetation structure ( $\geq 5 \mathrm{~cm}$ in $\mathrm{DBH}$ ) showed little change despite a high density of deer between 1990 and 2002 in this area. They proposed three factors to explain this result: 1) small body size of $C$. $n$. yakushimae subspecies; 2) the carrying capacity of evergreen forests may be higher than that of deciduous forests, particularly in winter; 3 ) the forest and deer populations in the study area have long coexisted without the complicating factors of predation or other significant disturbance (Agetsuma et al. 2003).

The effects of bark stripping were most apparent on smaller diameter trees, with tree death occurring when 
complete girdling occurred (Akashi and Nakashizuka 1999). Others have reported widespread tree losses and lack of recruitment due to feeding pressure from high density sika deer populations (Akashi and Nakashizuka 1999; Yokoyama et al. 2000). Feeding on seedlings and physical disturbance by numerous deer affect seedling mortality and survivability of both preferred species non-preferred species (Tsujino and Yumoto 2004). While the sika deer population in our study area increased over these 13 years, its impact on forest regeneration is not well documented. Ongoing studies of this subspecies and its unique habitat should monitor both changes in deer numbers and distribution, as well as impacts on forest regeneration.

Acknowledgments: We would like to thank my friends and colleagues in Yakushima for their hospitality and help during the fieldwork. We are also grateful for Yakushima Forest Environment Conservation Center for permission to undertake the research. Sarugoyacommittee and Field Research Center of Primate Research Institute, Kyoto University offered me excellent facilities. Drs. N. Agetsuma, S. Aiba, G. Hanya, S. Hayaishi, K. Kitayama and members at Center for Ecological Research, Kyoto University offered me helpful suggestions and comments on the manuscript. This study is partly supported by a Grant-in-Aid for the 21 st Century COE Research (Kyoto University, A2) and Research Project 'Evaluation of sustainable forest use options and their perspectives of the Research Institute for Humanity and Nature. We also thank anonymous reviewers and Dr J. Moll for their helpful comments on the manuscript.

\section{References}

Agetsuma, N. 1995. Dietary selection by Yakushima macaque (Macaca fuscata yakui): The influence of food availability and temperature. International Journal of Primatology 16: 611-627.

Agetsuma, N. 1998. Crop damage by wild Japanese monkeys on Yakushima Island, Japan. Japanese Journal of Conservation Ecology 3: 43-55 (in Japanese with English summary).

Agetsuma, N. 1999. Present situation of Japanese wild life reviewed from economic backgrounds: An introdustion for young students. Akita University of Economics and Law The Journal of Economics Department 30: 11-23.

Agetsuma, N., Sugiura, H., Hill, D. A., Agetsuma-Yanagihara, Y. and Tanaka, T. 2003. Population density and group composition of Japanese sika deer (Cervus nippon yakushimae) in evergreen broad-leaved forest of Yakushima, southern Japan. Ecological Research 18: 475-483.

Agetsuma, N., Sugiura, H. and Tanaka, T. 1994. Influence of Seibu Road on the World Heritage Forest on Yakushima Island, Japan.
Primate Research 10: 41-47 (in Japanese with English summary). Akashi, N. and Nakashizuka, T. 1999. Effects of bark-striping by Sika deer (Cervus nippon) on population dynamics of a mixed forest in Japan. Forest Ecology and Management 113: 75-82.

Anderson, D. R., Laake, J. L., Crain, B. R. and Burnham, K. P. 1979. Guidelines for line tranects sampling of biological populations. Journal of Wilidlife Management 43: 70-78.

Asada, M. and Ochiai, K. 1996. Food habitats of sika deer on the Boso Peninsula, central Japan. Ecological Research 11: 89-95.

Bratton, S. P. 1974. The effect of the European wild boar (Sus scrofa) on the high-elevation vernal flora in Great Smoky Mountains National Park. Bulletin of the Torrey Botanical Club 101: 198206.

Buckland, S. T., Anderson, D. R., Burnham, K. P. and Laake, J. L. 1993. Distance Sampling: Estimation Abundance of Biological Populations. Chapman and Hall, London, 446 pp.

Focardi, S., Isotti, R. and Tinelli, A. 2002. Line transect estimates of ungulate populations in a mediterranean forest. Journal of Wildlife Management 66: 48-58.

Gill, R. M. A., Thomas, M. L. and Stocker, D. 1997. The use of portable imaging for estimating deer population density in forest habitats. Journal of Applied Ecology 34: 1273-1286.

Griffin, J. R. 1971. Oak regeneration in the upper Carmel Valley, California. Ecology 52: 862-868.

Hiby, L. and Krishna, M. B. 2001. Line transect sampling from a curving path. Biometrics 57: 727-731.

Hobbs, N. T., Baker, D. L., Ellis, J. E. and Swift, D. M. 1981. Composition and quality of elk winter diets in Colorado. Journal of Wildlife Management 45: 156-171.

Ickes, K., Dewalt, S. J. and Appanah, S. 2001. Effects of native pigs (Sus scrofa) on woody understorey vegetation in a Malaysian lowland rain forest. Journal of Tropical Ecology 17: 191-206.

Ida, H. and Nakagoshi, N. 1996. Gnawing damage by rodents to the seedlings of Fagus crenata and Quercus mongolica var. grosseserrata in a temperate Sasa grassland-deciduous forest series in southwestern Japan. Ecological Research 11: 97-103.

Kagosimaken Sizen-aigo Kyokai 1981. Yakusika no seisoku/bunpu nikansuru kinkyu chousa houkokusho. Kagoshimaken Sizen-aigo Kyokai Chousahoukoku 5: 1-34 (in Japanese).

Kaji, K. 1995. Deer irruptions - A case study in Hokkaido, Japan. Honyurui Kagaku [Mammalian Science] 35: 35-43.

Kikuzawa, K. 1988. Dispersal of Quercus mongolica acorns in a broadleaved deciduous forest. Forest Ecology and Management 25: $1-8$.

Matsuda, H., Kaji, K., Uno, H., Hirakawa, H. and Saitoh, T. 1999. A management policy for sika deer based on sex-specific hunting. Research of Population Ecology 41: 139-149.

Matsuda, H., Uno, H., Tamada, K., Kaji, K., Saitoh, T., Hirakawa, H., Kurumada, T. and Fujimoto, T. 2002. Harvest-based estimation of population size for Sika deer on Hokkaido island, Japan. Wildlife Society Bulletin 30: 1160-1171.

McCarthy, B. C. and Facelli, J. M. 1990. Microdisturbances in oldfields and forests: implications for woody seedling establishment. Oikos 58: 55-60.

McLean, C. 1999. The effect of deer culling on tree regeneration on Scaniport Estate, Inverness-shire: A study by the Deer Commission for Scotland. Scottish Forestry 53: 225-230.

Miura, K. 1984. Natural conservation in Yakushima Island. Monkey 28: 64-69 (in Japanese).

Noma, N. 1997. Annual fluctuations of sapfruits production within and inter species in a warm Temperate forest on Yakushima Island. Tropics 6: 441-449.

Nomiya, H., Suzuki, W., Kanazashi, T., Shibata, M., Tanaka, H. and 
Nakashizuka, T. 2003. The response of forest floor vegetation and tree regeneration to deer exclusion and disturbance in a riparian deciduous forest, central Japan. Plant Ecology 164: 263-276.

Pease, J. L., Vowles, R. H. and Keith, L. B. 1979. Interaction of snowshoe hares and woody vegetation. Journal of Wildlife Management 43: 43-60.

Ruette, S., Stahl, P. and Albaret, M. 2003. Applying distance-sampling methods to spotlight counnts of red foxes. Journal of Applied Ecology 40: 32-43.

Sakata, H., Hamasaki, S., Kishimoto, M., Mitsuhashi, H., Mitsuhashi, A., Yokoyama, M. and Mitani, M. 2001. The relationships between Sika deer density, hunting pressure and damage to agriculture in Hyogo Prefecture. Humans and Nature 63-72 (in Japanese with English abstract).

Sekine, T. and Sato, H. 1992. Tree barking by sika deer, Cervus nippon TEMMINCK, on Mt. Odaigahara. Japanese Journal of Ecology 42: 241-248 (in Japanese with English synopsis).

Shaw, M. W. 1968. Factors affecting the natural regeneration of sessile oak (Quercus petraea) in north Wales II. Acorn losses and germination under field condition. Journal of Ecology 56: 647660 .

Shimoda, K., Kimura, K., Kanzaki, M. and Yoda, K. 1994. The regeneration of pioneer tree species under browsing pressure of Sika deer in an evergreen oak forest. Ecological Research 9: 85-92.

Tagawa, H. 1980. Vegetation on the western slope of Mt. Kuniwaridake, Yakushima Island. Science reports of Kagoshima University 29: 121-137 (in Japanese).

Takatsuki, S. 1988. Rumen contents of sika deer on Tsushima Island, western Japan. Ecological Research 3: 181-183.
Takatsuki, S. 1990. Summer dietary compositions of sika deer on Yakushima Island southern Japan. Ecological Research 5: 253260.

Takatsuki, S. and Gorai, T. 1994. Effects of Sika deer on the regeneration of a Fagus crenata forest on Kinkazan Island, northern Japan. Ecological Research 9: 115-120.

Tardiff, S. E. and Stanford, J. A. 1998. Grizzly bera digging: effects on subalpine meadow plants in relation to mineral nitrogen availability. Ecology 79: 2219-2228.

Thomas, L., Laake, J. L., Strindberg, S., Marques, F. F. C., Buckland, S. T., Borchers, D. L., Anderson, D. R., Burnham, K. P., Hedley, S. L., Pollard, J. H. and Bishop, J. R. B. 2003. Distance 4.1. Release 2. Research Unit for Wildlife Population Assessment, University of St. Andrews, UK. http://www.ruwpa.st-and.ac.uk/ distance/

Tsujino, R. and Yumoto, T. 2004. Effects of sika deer on tree seedlings in a warm temperate forest on Yakushima Island, Japan. Ecological Research 19: 291-300.

Uno, H., Yokoyama, M. and Takahashi, M. 1998. Winter mortality pattern of Sika deer (Cervus nippon yesoensis) in Akan National Park, Hokkaido. Honyurui Kagaku [Mammalian Science] 38: 233-246 (in Japanese with English abstract).

Weerasinghe, U. R. and Takatsuki, S. 1999. A record of acorn eating by sika deer in western Japan. Ecological Research 14: 205-209.

Yokoyama, M., Kaji, K. and Suzuki, M. 2000. Food habitats of sika deer and nutritional value of sika deer diets in eastern Hokkaido, Japan. Ecological Research 15: 345-355.

Received 5 September 2003. Accepted 14 June 2004. 